\title{
Bacterial microbiota composition of Ixodes ricinus ticks: the role of environmental variation, tick characteristics and microbial interactions
}

\author{
Tuomas Aivelo ${ }^{\text {Corresp., } 1,2}$, Anna Norberg ${ }^{1}$, Barbara Tschirren ${ }^{3}$ \\ 1 Organismal and Evolutionary Biology research program, University of Helsinki, Helsinki, Finland \\ 2 Department of Evolutionary Biology and Environmental Studies, University of Zurich, Zurich, Switzerland \\ 3 Centre for Ecology and Conservation, University of Exeter, Penryn, United Kingdom \\ Corresponding Author: Tuomas Aivelo \\ Email address: tuomas.aivelo@helsinki.fi
}

Ecological factors, host characteristics and / or interactions among microbes may all shape the occurrence of microbes and the structure of microbial communities within organisms. In the past, disentangling these factors and determining their relative importance in shaping within-host microbiota communities has been hampered by analytical limitations to account for (dis)similar environmental preferences ('environmental filtering'). Here we used a joint species distribution modelling (JSDM) approach to characterize the bacterial microbiota of one of the most important disease vectors in Europe, the sheep tick Ixodes ricinus, along ecological gradients in the Swiss Alps. Although our study captured extensive environmental variation along elevational clines, the explanatory power of such large-scale ecological factors was comparably weak, suggesting that tick-specific traits and behaviours, microhabitat and -climate experienced by ticks, and interactions among microbes play an important role in shaping tick microbial communities. Indeed, when accounting for shared environmental preferences, evidence for significant patterns of positive or negative co-occurrence among microbes was found, which is indicative of competition or facilitation processes. Signals of facilitation were observed primarily among human pathogens, leading to co-infection within ticks, whereas signals of competition were observed between the tick endosymbiont Spiroplasma and human pathogens. These findings highlight the important role of small-scale ecological variation and microbemicrobe interactions in shaping tick microbial communities and the dynamics of tick-borne disease. 
1 Bacterial microbiota composition of Ixodes ricinus ticks: the role of environmental variation, tick

2 characteristics and microbial interactions

3

4 Tuomas Aivelo ${ }^{1,2}$, Anna Norberg ${ }^{2}$, Barbara Tschirren ${ }^{3}$

5 1: Department of Evolutionary Biology and Environmental Studies, University of Zurich, Zurich,

6 Switzerland

7 2: Organismal and Evolutionary Biology research program, University of Helsinki, Finland

8 3: Centre for Ecology and Conservation, University of Exeter, United Kingdom

9

10 Corresponding author: Tuomas Aivelo

11 Email: tuomas.aivelo@helsinki.fi 


\section{Abstract}

13 Ecological factors, host characteristics and / or interactions among microbes may all shape the

14 occurrence of microbes and the structure of microbial communities within organisms. In the past,

15 disentangling these factors and determining their relative importance in shaping within-host

16 microbiota communities has been hampered by analytical limitations to account for (dis)similar

17 environmental preferences ('environmental filtering'). Here we used a joint species distribution modelling (JSDM) approach to characterize the bacterial microbiota of one of the most important

19 disease vectors in Europe, the sheep tick Ixodes ricinus, along ecological gradients in the Swiss Alps. Although our study captured extensive environmental variation along elevational clines,

21 the explanatory power of such large-scale ecological factors was comparably weak, suggesting

22 that tick-specific traits and behaviours, microhabitat and -climate experienced by ticks, and

23 interactions among microbes play an important role in shaping tick microbial communities.

24 Indeed, when accounting for shared environmental preferences, evidence for significant patterns

25 of positive or negative co-occurrence among microbes was found, which is indicative of

26 competition or facilitation processes. Signals of facilitation were observed primarily among

27 human pathogens, leading to co-infection within ticks, whereas signals of competition were

28 observed between the tick endosymbiont Spiroplasma and human pathogens. These findings

29 highlight the important role of small-scale ecological variation and microbe-microbe interactions

30 in shaping tick microbial communities and the dynamics of tick-borne disease.

31 Keywords: tick-borne pathogens, species distribution modelling, community composition,

32 Borrelia burgdorferi, Lyme disease 


\section{Introduction}

Microbial communities within organisms consist of symbionts, commensals, mutualists and pathogens that co-occur simultaneously and potentially influence each other (Petney and Andrews 1998; Rigaud et al. 2010; Sofonea et al. 2015). These microbial communities may be shaped by a range of factors and processes, including the environment, host and microbe genetics and the occurrence and abundance of other microbial species (Adair and Douglas 2017). For example, certain microbial species might tolerate only specific abiotic conditions, which makes it more likely that species with similar requirements co-occur within a host ('environmental filtering', Dallas and Presley, (2014)). Similarly, the host's immune system can influence colonization success of microbes (Hawley and Altizer 2011), with cross-immunity preventing the colonization of different microbes with similar antigenic properties (Durand et al. 2015).

Furthermore, mutualistic interactions between hosts and microbes can influence the structure of bacterial communities within host individuals (Chu and Mazmanian 2013; Lee et al. 2013). Finally, direct interactions among microbes might affect colonization, or replication success after colonization, through competition or facilitation processes. Competition may occur when different microbes use the same, limited resources within a host (Lello et al. 2004), whereas facilitation may occur directly through the production of public goods (West and Buckling 2003) or indirectly through the modification of the host's physiology (Abraham et al. 2017) or immune defense (Rodríguez et al. 1999).

Ixodes ricinus is the most common tick species in Europe and an important vector for a range of human, domestic animal and wildlife pathogens (Medlock et al. 2013). Its distribution and abundance are strongly influenced by environmental conditions, in particular temperature and humidity (Cortinas et al. 2002; Gatewood et al. 2009). Previous studies that characterized the 
56 bacterial community composition of I. ricinus ticks have found mostly environmental and free-

57 living bacteria but also several endosymbionts and human, domestic animal or wildlife

58 pathogens, including Borrelia (Mannelli et al. 2012), Rickettsia (Venclikova et al. 2014),

59 Anaplasma (Jahfari et al. 2014) and Candidatus Neoehrlichia (Kawahara et al. 2004).

60

61

62

63

64

Differences in the bacterial community structure and composition of ticks across habitats (Estrada-Peña et al. 2018), geographical sites (Carpi et al. 2011), and tick life stages and sexes (Carpi et al. 2011; Vayssier-Taussat et al. 2013) have been documented. Large-scale biotic or abiotic factors such as vegetation structure, elevation, temperature or rainfall may influence tick microbial communities directly, or indirectly through effects on tick physiology or activity patterns (van Treuren et al. 2015) or via influencing the distribution and abundance of tick hosts species (Randolph et al. 1999; MacDonald et al. 2017). Small-scale and/or tick-specific effects on microbial communities may be explained by microhabitat or microclimatic conditions experienced by individual ticks (Gern et al. 2008), individual tick behavior or genetics (Hawlena et al. 2013), direct biotic interactions among microbes (Moutailler et al. 2016) or parallel acquisition from a host during a bloodmeal (Andersson et al. 2014; Belli et al. 2017; Swei and Kwan 2017).

Currently, the relative importance of these factors in shaping tick microbial communities is not well understood, which hampers progress in our understanding of the processes shaping microbial communities in nature and predicting the occurrence of specific microbes (e.g., human pathogens). Elevational gradients are excellently suited to quantify the importance of large-scale ecological variation in shaping tick bacterial microbiota because they cover a large range of environmental conditions within a small geographical area. Furthermore, including replicated 
78

79

80

81

82

83

84

85

86

87

88

89

90

91

92

93

94

95

96

97

98

99

100

transects along gradients allow us to quantify the robustness of ecological associations within sites and along elevational clines on tick microbial communities.

Ixodes ticks are commonly found to be co-infected with several (human, domestic animal and/or wildlife) pathogens (Andersson et al. 2013; Michelet et al. 2014; Diuk-Wasser et al. 2016;

Moutailler et al. 2016). Currently, it is unknown whether these co-infection patterns are caused by similar environmental preferences of pathogens, parallel acquisition from host communities or direct microbe-microbe interactions within ticks. Yet, previous studies suggest that the latter process, (i.e., facilitation and competition processes among microbes) may play a role in shaping microbial communities (Haine 2008; Bonnet et al. 2017). For example, it has been found that pathogenic Rickettsia species prevent co-infection with other Rickettsia species in Dermacentor variabilis ticks (Macaluso et al. 2002), whereas the presence of Francisella sp. endosymbionts increases the colonization success of pathogenic Francisella novicida in D. andersoni ticks (Gall et al. 2016). Facilitation has also been suggested to promote co-infection with different Borrelia afzelii strains in Ixodes ricinus ticks (Andersson et al. 2013). Most strikingly, dysbiosis in I. scapularis ticks (i.e., ticks with low microbiotal diversity) leads to a defective peritrophic matrix which decreases the colonization success of B. burgdorferi s.s., suggesting that the pathogen requires the presence of an intact microbiota to be able to invade ticks (Narasimhan et al. 2014). Thus, the microbial community may have a crucial impact on vector competence of ticks and thereby on disease dynamics.

Yet, as outlined above, co-occurrence of microbes can be due to environmental filtering or direct microbial interactions, and distinguishing between these processes is non-trivial. Indeed, previous studies that have documented pathogen co-occurrence in ticks have not accounted for potential confounding variables such as shared ecological requirements, and are thus limited in 
101 their ability to differentiate between co-occurrences due to shared environmental niches, and co-

102 occurrence shaped by facilitation or competition among microbes.

103 To address these gaps, we exploited the substantial environmental heterogeneity along replicated 104 elevational gradients in the Swiss Alps to quantify the relative importance of environmental 105 factors, tick characteristics and direct microbial interactions in influencing the structure of 106 bacterial communities in I. ricinus ticks in general, and the (co-)occurrence of pathogens in 107 particular, using a combination of $16 \mathrm{~S}$ sequencing and joint species distribution modelling 108 (JSDM) (Ovaskainen et al. 2015; Warton et al. 2015). By taking shared environmental 109 preferences into account, JSDMs allows to identify residual co-occurrence patterns among 110 microbes that can result from unaccounted environmental effects or direct microbial interactions.

111 However, the correct spatial scale with regards to the focal biological processes is of importance, 112 as well as the type of the hypothesized biotic interaction (Araújo and Rozenfeld 2014; Zurell et 113 al. 2018) when interpreting JSDM patterns (Dormann et al. 2018).

114 Specifically, we ask (i) how do large-scale abiotic factors and small scale tick-level variables 115 affect tick microbiota composition, (ii) which large-scale abiotic and small-scale tick-level 116 variables predict pathogen occurrence, and (iii) are there patterns of non-random microbial co-

117 occurrence that cannot be explained by environmental responses and might be due to 118 unmeasured variables, such as microbial interactions. 
123 Questing Ixodes ricinus ticks were collected at three locations in the Swiss Alps (Kanton

124 Graubünden). At each location, one site at low (630 - $732 \mathrm{~m}$ above sea level, masl), one at

125 medium (1 094 - 1138 masl) and one at high (1 454 - 1673 masl) elevation were identified

126 (Fig. 1, Table 1, N =9 sampling sites). At each site, questing ticks were sampled thrice, once in

127 June, once in July, and once in August 2014 by dragging a white blanket (1 m x $1 \mathrm{~m})$ over the

128 ground vegetation as described previously (Lemoine et al. 2018). Ticks were collected from the

129 blanket and stored in 95\% ethanol. Tick species, sex and life stage were verified by

130 morphological features following (Hillyard 1996) using a stereomicroscope.

\section{Environmental variables}

133 For each sampling site, we compiled information on large-scale, site-level ecological variables

134 by obtaining data on elevation, slope and aspect using DHM25, land use data from swissTLM3D

135 (both from Federal Office of Topography swisstopo) and data on temperature and precipitation

136 from Landscape Dynamics (Swiss Federal Research Institute for Water, Snow and Landscape

137 Research WSL and Federal Office of Meteorology and Climatology MeteoSwiss, (Thornton et

138 al. 1997)). Data on I. ricinus abundance and the abundance of a key tick host, the bank vole

139 (Myodes glareolus), as well as the ratio of bank vole to other rodents at our sampling sites were

140 obtained from Cornetti et al. (2018). Details on the different variables and a justification why

141 they were included to characterise large-scale ecological conditions is provided in the

142 Supplementary Material.

144 Tick DNA isolation and quantification of neutral genetic diversity 
145 The number of analysed ticks per site is presented in Table 1. Although we aimed to include

146 similar numbers of $I$. ricinus ticks from each sampling site and month, variation in the number of

147 ticks per site (Table 1) was unavoidable because of variation in tick abundance across sites

148 (Lemoine et al. 2018). To avoid contamination, we performed DNA isolation and amplifications

149 in a laminar flow cabinet. Each tick was washed thrice with sterile water before sterilizing it with

$1503 \%$ hydrogen peroxide. Ticks were then cut in half with a sterilized blade to facilitate DNA

151 isolation. DNA was extracted using DNeasy Blood \& Tissue kit (Qiagen; Hilden, Germany).

152 Host genetics may affect pathogen and endosymbiont colonisation and replication success

153 (Archie and Ezenwa 2011). In order to quantify individual and population-level genetic diversity,

154 we genotyped ticks at 11 microsatellite markers in two multiplexed amplifications (see

155 Supplementary Material for details). Not all markers were successfully amplified in all samples,

156 but none of the samples contained more than two failed markers. We used package poppr

157 (Kamvar et al. 2014) in R 3.4.1 (Team 2013) to test for linkage disequilibrium and deviation

158 from Hardy-Weinberg equilibrium. Individual observed heterozygosity was determined for each

159 tick as a proportion of heterozygous markers to all successfully amplified markers. Expected

160 population level heterozygosity was determined with poppr. The former was used as a tick-level

161 explanatory variable (together with tick sex and life stage), the latter was used as a site-level

162 explanatory variable.

\section{Tick microbiota sequencing}

165 We characterized tick bacterial community composition by sequencing the hypervariable V4 166 region of the $16 \mathrm{~S}$ rRNA (16S) gene. Negative controls (extraction reagent blank, N=2 and PCR 
167 controls, $N=3$ ) were processed alongside the tick samples. Sequencing libraries were prepared

168 following the Earth Microbiome 16S Illumina Amplicon protocol, using the primers 515FB and

169 806RB (Carey et al. 2013) (see Supplementary Material for details). Samples and negative

170 controls were randomized across two plates. The libraries were sequenced on Illumina MiSeq at

171 the Functional Genomic Center Zurich with a target length of $250 \mathrm{bp}$ following the

172 manufacturer's protocol. The obtained sequence data were analyzed following the mothur 173 pipeline with MiSeq standard operation procedures (Kozich et al. 2013). Sequences have been

174 deposited to the Sequence Read Archive under BioProject PRJNA506875. The complete

175 metadata of the samples and their matching sequence accession numbers have been submitted to

176 FigShare (doi: 10.6084/m9.figshare.7380767).

177 As we are not able to assess whether individual OTUs are resident or not, and we do not know

178 their transmission routes, a special focus of our analysis was on tick endosymbionts and tick-

179 borne human, domestic animal or wildlife pathogens (Table 2), which are obligate residents. This

180 approach does not mean that the other OTUs would not have a substantial effects on ticks and

181 other tick symbionts. Identification of endosymbionts and pathogens is described in the

182 Supplementary Material.

Joint species distribution modelling of microbiota composition

185 Only samples with $>500$ reads and OTUs which were present in at least two samples were

186 included in the analyses (Table 1). As the most common OTU, the intra-mitochondrial

187 endosymbiont Candidatus Midichloria (Lo et al. 2006), was present in all samples, it was not 
188 included in the modelling. For the occurrence matrix, an OTU was determined to be present in a

189 tick if $>5$ reads were identified in a sample (following Aivelo and Norberg 2017).

190 We used a JSDM framework called Hierarchical Modelling of Species Communities (HMSC,

191 Ovaskainen et al. 2017a) to examine how environmental variables correlate with pathogen and

192 tick endosymbiont occurrence in ticks, and whether there are non-random residual associations

193 among different OTUs and/or oligotypes, implying direct facilitation or competition effects

194 among microbes. This approach combines information on environmental covariates, bacterial

195 species traits, spatiotemporal context and sampling design to explain the presence or absence of

196 OTUs (Fig. S2). The associations among OTUs are captured with the latent part of the

197 framework, modelling the residual variance after accounting for the effects of the environment

198 with latent variables. The estimates for these latent variables can be then translated into residual

199 correlations among response variables, i.e. OTUs and/or oligotypes. These correlations thus

200 reflect (dis)associations which cannot be explained by shared responses to the environment.

201 We compiled occurrence matrices for OTUs for each individual tick as a response variable. For

202 each sampling unit, i.e. a row in our response variable matrix, we included information on the

203 identity of the sampling unit (tick ID), its location, sampling site (for which we included also the

204 spatial structure as coordinates) and month, describing the study design. To reach a better

205 resolution within specific OTUs, we analyzed known human, domestic animal or wildlife

206 pathogens, tick endosymbionts and their close relatives within the 100 most common OTUs with

207 oligotyping pipeline (Eren et al. 2014). Oligotyping uses all the sequences, which form an OTU, 208 and performs Shannon Entropy Analysis to regroup sequences based on within-OTU variation.

209 This results in higher-resolution grouping than OTUs as the different oligotypes might differ

210 only by a single nucleotide (Eren et al. 2014). We used the standard operation procedures of the 
211 oligotyping pipeline software (http://oligotyping.org; Eren et al. 2013). We labelled the resulting

212 oligotypes through BLAST search (Camacho et al. 2009). For some species, such as Rickettsia

213 spp., the V4 region of $16 \mathrm{~S}$ might not have enough resolution (Greay et al. 2018), and thus, the

214 labels should not be considered as definite identifications.

215 Including a large number of explanatory variables in statistical models is inherently challenging.

216 To reduce the number of variables, while maintaining their information value, we used two

217 variable sets in the model: a) a set of full-effect explanatory variables, and b) explanatory

218 variables under variable selection (Ovaskainen et al. 2017b). The full-effect variable set included

219 an intercept, two tick-level variables (tick sex or life stage and individual heterozygosity) and

220 two site-level variables (tick abundance and elevation of the sampling site). Additionally, we

221 included information whether a specific OTU is an endosymbiont and/or a human, domestic

222 animal or wildlife pathogen (Abrego et al. 2016). This allowed us to test if endosymbionts and/or

223 pathogens respond differentially to environmental conditions than other OTUs. The set of

224 explanatory variables under variable selection included additional information on the

225 environmental conditions of the sites (namely the number of days above $7^{\circ} \mathrm{C}$ during the year,

226 monthly precipitation, mean monthly temperature, forest coverage, slope, aspect, bank vole

227 abundance, the proportion of voles to other rodents and expected tick heterozygosity) (Table S1).

228 We considered all parameter estimates, including associations among bacterial OTUs, having

229 strong statistical support and thus being 'significant" if the $90 \%$ central credible interval of the

230 parameter did not overlap with zero (see Supplementary Material for additional model details).

231 The model was run in Matlab R2017 (The MathWorks; Natick, MA, USA). 
235 Ixodes ricinus microbiota composition

236 We 16S sequenced the bacterial community of 92 Ixodes ricinus ticks which resulted in 13214

237477 reads. No amplification was observed in the five negative controls (i.e., their sequencing did

238 not result in any reads) and one tick was sequenced twice. After contig assembly and quality

239 control 1656287 reads were retained. Most of the discarded reads were either shorter than 250

240 bp or chimeras. There was a median of 1562 quality-controlled reads per sample, with an

241 interquartile range of 6319.82 samples with more than 500 reads per sample, a plateauing

242 accumulation curve and a Good's coverage estimator $\geq 0.95$ were included in the subsequent

243 analyses (Fig. S1). In total, 5181 bacterial OTUs were identified. The median number of OTUs

244 when rarified to 500 reads per sample was 89 OTUs, with a 95\% confidence interval of 78.3 -

24598.5 OTUs.

246 Six OTUs were present in at least 90\% of the samples: $\mathrm{Ca}$. Midichloria (Otu0001),

247 Sphingomonas (Otu0002, 0006 and 0007), Pseudomonas (Otu0011) and Delftia (Otu0012).

248 Together, they represented 50.2\% of all reads. We used oligotyping to further divide OTU0031

249 'Rickettsia' into two oligotypes labelled as ' $R$. helvetica' and ' $R$. monacensis', and OTU0086

250 'Borrelia' into four oligotypes labelled as 'B. afzelii', 'B. valaisiana' and 'B. garinii' and ' $B$.

251 miyamotoi’. 635 OTUs and oligotypes were used in subsequent analyses, including 14

252 endosymbionts and / or human, domestic animal or wildlife pathogens (Table 2).

253

254 Tick microbiota variance partitioning 
255 Variance partitioning revealed that most of the variation in tick microbiota composition

256 explained by our model related to tick ID: for the hundred most common OTUs, tick ID

257 accounted for $64.1 \%$ of the variation explained by the model. Fixed effects (e.g., tick life stage,

258 elevation; see Table S1) accounted for 12.5\% (tick-level: 7.3\%, site-level: 5.2\%) and spatial and

259 temporal random effects (i.e., location, site and month) explained 23.3\% (Fig. 2). This suggests

260 that there is extensive tick-level variation which cannot be accounted for by tick-specific

261 characteristics included in our model (i.e., sex, life stage, genetic diversity) or site-level

262 environmental factors. The pattern differed slightly for endosymbionts and human, domestic

263 animal or wildlife pathogens: while tick ID was still the most important variable explaining

264 49.9\%, fixed effects explained 31.8\% (tick-level: 17.5\%, site-level: 14.3\%) and spatial and

265 temporal random effects explained $18.3 \%$ of the total variation explained by the model, when

266 averaged over all pathogens and endosymbionts (Fig. 2). Thus, tick- and site-level fixed effects

267 explained a larger proportion of the variation in the occurrence of obligate resident pathogens

268 and endosymbionts than the occurrence of other (potentially non-resident) OTUs.

Tick-specific and environmental factors related to OTU occurrence

271 The occurrence of tick endosymbionts and pathogens was strongly associated with specific

272 explanatory variables, yet associations were typically microbe-specific rather than universal

273 (Table 3). The two most important variables explaining the presence or absence of tick

274 endosymbionts and human, domestic animal or wildlife pathogens were tick sex and elevation of

275 the sampling site: adult female ticks were less likely to harbour the endosymbionts Spiroplasma, Rickettsiella, Lariskella and Rickettsia spp. (Table 3), and ticks at higher elevations had higher

277 probability to harbour $R$. helvetica and $R$. monacensis, but were less probable to harbour $B$. 
278 garinii (Table 3). Slope and aspect were also significant predictors of tick endosymbionts and

279 pathogen occurrence, with ticks from sites facing northwards having a higher probability of

280 harbouring Spiroplasma and B. afzelii, and ticks from sites on steeper slopes having a higher

281 probability of harbouring Rickettsia sp. (Table 3). Furthermore, a higher tick abundance was

282 associated with a higher probability of Rickettsiella and $\mathrm{Ca}$. Neoehrlichia occurrence (Table 3).

283 Relationships between tick life stage, mean temperature, the number of days $>7{ }^{\circ} \mathrm{C}$ or forest

284 cover and the occurrence of specific OTUs were not strongly statistically supported.

285 The effect sizes of strongly statistically supported associations varied substantially (Fig. S4a-i).

286 For example, threefold increase in vole abundance corresponded to less than one percentage

287 point decrease of $R$. monacensis prevalence (Fig. S4b), whereas a threefold increase in tick

288 abundance corresponded to a threefold increase in Neoehrlichia prevalence from $8 \%$ to $27 \%$

289 (Fig. S4e).

290

291

Patterns of microbial association within ticks

292 Numerous bacterial OTUs were either significantly more or less likely to co-occur within a tick

293 than expected by chance after accounting for shared environmental preferences (Fig. 3a; Table

294 S2). At the level of the individual tick, the occurrence of the tick endosymbiont Spiroplasma was

295 negatively associated with the occurrence of the endosymbiont Lariskella and several tick-borne

296 pathogens, namely Rickettsia sp., Ca. Neoehrlichia and B. miyamotoi (Fig. 3a). Associations

297 among pathogens, if they occurred, were all positive (Fig. 3a), suggesting that ticks are more

298 likely to be co-infected with several human, domestic animal or wildlife pathogens

299 simultaneously than expected by chance or based on shared environmental preferences. Borrelia

Peer] reviewing PDF | (2019:09:41295:1:1:NEW 3 Nov 2019) 
300 oligotypes showed positive co-occurrence patterns among each other, except for B. miyamotoi,

301 which was not associated with other Borrelia sp., but negatively with Spiroplasma and positively

302 with Lariskella. At the level of the sampling site, significant associations were sparser.

303 Spiroplasma was more likely to co-occur with Lariskella and Rickettsiella across sites, whereas

304 the latter two were less likely to co-occur across sites than expected by chance after accounting

305 for shared environmental preferences (Fig. 3b). At the level of month or location, there were no 306 significant associations.

\section{Discussion}

We used a JSDM framework to quantify the relative importance of large scale, site-level environmental variables, tick-level characteristics and interactions among microbes in shaping tick microbiota composition along elevational gradients in the Swiss Alps. We show that although our study captured extensive environmental variation, with sampling sites spanning across an elevational gradient from 630 - 1580 masl, and a large number of ecological variables was considered in our models, the explanatory power of such large-scale ecological factors was comparably weak. In contrast, individual tick ID explained over $60 \%$ of the variation in microbiota composition. This substantial microbiota variation across individual ticks may be partly explained by some of the bacteria present in ticks being non-resident (i.e., bacteria that were by chance obtained from the environment through the mouth, the anal pore or spiracles or during blood-feeding; Horner-Devine and Bohannan 2006; Engel and Moran 2013; Zolnik et al.

320 2016, 2018; Ross et al. 2018). Indeed, there has been a debate whether ticks have a stable

322 in arthropod hosts (Hammer et al. 2017). 
323 However, also for endosymbionts and human, domestic animal or wildlife pathogens, which are

324 obligate resident, tick ID accounted for half of the variation in occurrence, suggesting that

325 microhabitat or -climatic conditions experienced by individual ticks, tick-specific traits and

326 behaviors not included in our models, as well as microbial interactions within ticks such as

327 facilitation and competition (Abraham et al. 2017; Gurfield et al. 2017), play a crucial role in

328 shaping microbiota composition and the occurrence of endosymbionts and human or wildlife

329 pathogens in I. ricinus. Focusing on such small-scale variables, rather than large-scale climatic or

330 environmental factors as is usually done when modelling tick-borne pathogen prevalence

331 (Norman et al. 2016; Rosà et al. 2018), is thus likely a more fruitful approach to advance our

332 understanding of microbiota composition of natural populations as well as (tick-borne) disease

333 dynamics.

334 Co-occurrence of human, domestic animal or wildlife pathogens in ticks has been documented

335 previously, both in I. ricinus (Lommano et al. 2012; Michelet et al. 2014) and other tick species

336 (Gurfield et al. 2017; Laaksonen et al. 2018). Yet, previous studies did not control for

337 environmental filtering, which limited their ability to disentangle shared responses to the

338 environment from direct microbe-microbe interactions. Our study revealed that when accounting

339 for shared environmental preferences, associations among human or wildlife pathogens were

340 often pronounced and mostly positive. These positive associations may result from direct

341 facilitation among microbes or parallel colonization from co-infected tick hosts. Because our

342 sampling unit was the whole tick, whereas bacteria inhabiting a tick can be situated in different

343 organs, co-occurrence at the tick-level does not necessarily mean that there is direct interaction

344 between co-occurring OTUs, although indirect interactions, via, e.g., host immune system, can

345 still occur. 
347 Within ticks, the significant positive associations among the Lyme disease-causing Borrelia

348 genospecies (B. afzelii, B. garinii and B. valaisiana) were particularly striking. This positive co-

349 occurrence is surprising because B. garinii and B. valaisiana are bird specialists (Hanincova et

350 al. 2003b; Comstedt et al. 2011), whereas B. afzelii is a rodent specialist (Hanincova et al.

351 2003a). Thus, the parallel colonization from co-infected tick hosts cannot explain this pattern.

352 Rather the positive co-occurrence is indicative of facilitation processes among Borrelia

353 genospecies, as has been suggested previously (Andersson et al. 2013). Such facilitation, and the

354 resulting co-infection of ticks with several Borrelia genospecies has implications for the severity,

355 diagnosis, treatment and control of Lyme disease. Finally, the co-occurrence of these different

356 Borrelia genospecies suggests that I. ricinus feeds on multiple, phylogenetically diverse host

357 species during its life cycle and does not show pathogen-mediated host specialization as has been

358 suggested previously (McCoy et al. 2005, 2013).

359 Although associations among microbes were mostly positive, there were negative associations

360 between the tick endosymbiont Spiroplasma and several human or wildlife pathogens, which

361 may be explained by competition. The most common infection route for Spiroplasma is maternal

362 (i.e., vertical) transmission (Herren and Lemaitre 2011), indicating that horizontal or

363 environmental transfer plays a minor role in its transmission. Protective effects of Spiroplasma

364 have been previously described in Drosophila spp., where Spiroplasma is associated with a

365 decreased probability of nematode and parasitoids infections (Xie et al. 2010; Jaenike et al.

366 2013). Although the exact mechanisms mediating Spiroplasma-induced competition effects are

367 currently unknown, this finding may stimulate further research into the potential of tick

368 endosymbionts to manage tick-borne pathogens. 
369 In contrast to the numerous positive or negative associations among microbes at the tick-level,

370 little statistical support for positive or negative microbial co-occurrence was found at the site-

371 level, with the exception of the associations among three endosymbionts. Interestingly, the

372 pattern of co-occurrence of Spiroplasma and Lariskella at the site-level was opposite from what

373 was observed at the tick-level. It suggests that Spiroplasma and Lariskella are more likely to co-

374 occur at the same sites but not within the same tick. Co-occurrence at the site-level can be due to

375 an environmental variable not included in our model, for which the three OTUs had similar

376 responses. It has also been suggested that negative associations generate checkerboard patterns

377 of co-occurrence that can be captured at finer spatial scales but that are lost with increasing

378 scales, but positive associations can be captured across scales (Araújo \& Rozenfeld 2013).

379 Despite the large among-tick variation in microbiota composition, we identified a range of

380 environmental variables that significantly predicted the occurrence of specific tick

381 endosymbionts and human, domestic animal or wildlife pathogens. However, the predictor

382 variables as well as their effect were typically OTU-specific rather than universal. For example,

383 B. garinii was less likely to occur at higher elevations, whereas $R$. helvetica and $R$. monascensis

384 were more likely to occur at higher elevations. Generally, the environmental factors shaping

385 Rickettsia spp. distribution are poorly understood, as is their range of host species (Halos et al.

386 2010; Eremeeva and Dasch 2015). Yet, it has previously been found that spotted fever incidence

387 in humans, caused by $R$. ricketsii, is highest in areas or regions, where ticks are less common

388 (Atkinson et al. 2013). This is in line with our findings and suggests that Rickettsia spp. are more

389 likely to colonize ticks living under suboptimal conditions (e.g. at range edges).

390 The finding that $B$. garinii is less likely to occur at higher elevations is in line with previous

391 observations (Jouda et al. 2004b; Cornetti et al. 2018) and may be explained by changes in 
392 vegetation structure and associated changes in host communities (Halos et al. 2010), in particular

393 changes in the diversity and/or abundance of birds, the natural hosts of $B$. garinii (Comstedt et al.

394 2011). In contrast, the occurrence of the mammal specialist B. afzelii was not related to

395 elevation, potentially because elevational clines in mammal diversity and/or abundance are less

396 pronounced (McCain 2005). Indeed, we did not observe an association between elevation and

397 bank vole abundance across our study sites (ANOVA: $\left.F_{1,8}=0.357, p=0.57, R^{2}=0.05\right)$.

398

399

400

401

402

403

404

405

406

407

408

409

410

411

412

413

414

Interestingly, temperature and precipitation, which vary strongly across elevational gradients (average temperature and precipitation: high elevation sites: $11.8{ }^{\circ} \mathrm{C}$ and $17.8 \mathrm{~mm}$ per month; in low sites: $16.5^{\circ} \mathrm{C}$ and $12.1 \mathrm{~mm}$ per month), were not significant predictors of the occurrence of endosymbionts or human or wildlife pathogens, with the exception of precipitation correlating positively with the probability of Rickettsiella occurrence. This may be partly explained by the temperature and precipitation measures included in our models not fully capturing the microclimatic variation across sites and along elevational clines. Indeed, slope and aspect, which are important determinants of the topography, and thus microclimate (Bennie et al. 2008), were significant predictors of pathogen and endosymbiont occurrence. The probability of Rickettsia sp. occurrence was higher on steeper slopes. Furthermore, the probability of occurrence was higher on north-facing slopes for B. afzelii and Spiroplasma and higher on south-facing slopes for Rickettsiella (see also (Stuen et al. 2013)). Microclimatic conditions may affect microbial occurrence directly, or indirectly via affecting tick behavior or host community composition (Swei et al. 2011; Lawson et al. 2014). Furthermore, topography can affect population connectivity and dispersal in metapopulation networks (Swei and Kwan 2017).

Previous work has found that tick abundance is a strong predictor of Borrelia spp. prevalence, potentially because larger tick populations facilitate co-feeding transmission (Jouda et al. 2004a). 
415 No relationship between Borrelia spp. occurrence and tick abundance was observed in our study.

416 However, both $\mathrm{Ca}$. Neoehrlichia and Rickettsiella were more common at sites where ticks were

417 more abundant, suggesting that co-feeding transmission may also play a role in the life cycle of

418 these microbes.

419 Finally, differences in host competence can lead to dilution effects and thus affect the prevalence

420 of tick-borne pathogens (Keesing et al. 2006). Whereas for some tick-borne pathogens the

421 vertebrate hosts are known or suspected (e.g. small mammals for B. afzelii (Hanincova et al.

422 2003a) and Ca. Neoehrlichia (Jahfari et al. 2012), birds for B. garinii and B. valaisiana

423 (Hanincova et al. 2003b), both for Anaplasma (Keesing et al. 2012) and R. helvetica (Sprong et

424 al. 2009)), for others the host species range is less well understood (e.g. B. miyamotoi

425 ;Wagemakers et al. 2015). The bank vole is a common tick host at our study sites and their

426 abundance was a significant negative predictor of $R$. monacensis and $R$. helvetica occurrence.

427 Interestingly, bank voles are not known hosts for either (Burri et al. 2014). Most likely, the

428 relation is thus indirect, explained by an unmeasured biotic or abiotic variable that correlates

429 with bank vole abundance. No evidence was found that the proportion of bank voles to other

430 rodents affects the prevalence of tick-borne pathogens.

431 A limitation of our sampling design is the uneven sample distribution across sites. We collected

432 ticks up to the upper elevational limit of tick distribution, which leads to a large variation in

433 environmental variables included in our models, but at the same times means that we have a

434 limited number of samples from the high elevation sites. Yet, adequate model fit suggests that

435 this uneven sample distribution did not compromise model performance. Furthermore, although

436 JSDM is a powerful approach to model community structure, it has a number of limitations.

437 First, it assumes that interactions among microbes are similar across environments (but see 
438 Tikhonov et al. 2017). This is not necessarily the case as both environmental factors and tick host

439 community may shape microbial interactions (Elliot et al. 2002). Second, the model assumes that

440 the explanatory variables affect the microbial community composition (or rather, the presence or

441 absence of individual OTUs), but not vice versa. However, this is a valid assumption for most

442 environmental (e.g. elevation and temperature) and tick-related variables (e.g. tick sex, life stage)

443 included in our models. Thirdly, covariation among explanatory variables poses a problem to any

444 correlative modelling approach. Our model is built on two distinct variable sets to aid in handling

445 such covariation: the full variable set includes elevation, whereas the variables with the strongest

446 covariation (i.e., temperature and precipitation) are included in the variable selection set.

447 Fourthly, the inferred residual associations between focal taxa are assumed to be symmetrical. If

448 there are asymmetric interactions (e.g., predator-prey-relationships), the sum outcome can be

449 seen as either positive or negative correlation (Zurell et al. 2018). However, in our study, the

450 expectation was facilitation or competition, which are symmetric positive or negative

451 interactions, respectively. Thus, given sufficient signal, we expect that the focal interactions can

452 be captured by our modelling approach.

453

\section{Conclusions}

455

456

457

458

459

460

Our study demonstrates that a JSDM framework can contribute to a better understanding of the factors shaping bacterial communities in natural populations as well as patterns of co-occurrence among microbes. Overall, our study highlights the role of small-scale, tick-level characteristics rather than large-scale ecological variation in shaping microbial communities of I. ricinus. We identified a number of ecological variables that predict the occurrence of specific tick endosymbionts and human, domestic animal or wildlife pathogens with strong statistical support, 
461 but these effects were typically microbe-specific rather than universal. This highlights that

462 environmental change can have different, even opposite effects on different human pathogens,

463 and thus disease risk. Furthermore, by accounting for shared environmental preferences, our

464 approach identified patterns of microbial co-occurrence that are consistent with microbe-microbe

465 interactions, which result in pathogen co-infections within ticks, as well as competition between

466 Spiroplasma and a number of human, domestic animal or wildlife pathogens. The latter opens up

467 new and exciting avenues for the control and management of tick-borne diseases in regions with

468 high human disease incidence.

\section{Acknowledgements}

471 We thank Mélissa Lemoine for providing ticks, the numerous people who helped collecting ticks 472 in the field, Glauco Camenisch, Elisa Granato, Jennifer Morger and Alessia Pennachia for help 473 with laboratory work, Lucy Poveda for help with MiSeq sequencing, Frédéric Guillaume for 474 providing access to IT infrastructure, Janine Bolliger and Dirk Schmatz from Swiss Federal 475 Institute for Forest, Snow and Landscape Research WSL for providing spatial data and for help 476 with spatial analyses, and Otso Ovaskainen for discussions on the modelling and reviewers for 477 constructive comments on the manuscript.

\section{Funding statement}

This study was funded by Finnish Cultural Foundation Postdoc Pool grant (to TA), the Stiftung

481 für wissenschaftliche Forschung an der Universität Zürich (17_027), the Swiss National Science 482 Foundation (PP00P3_128386 and PP00P3_157455), the University of Zurich Research Priority 
483 Program "Evolution in Action: from Genomes to Ecosystems", the Faculty of Science of the 484 University of Zurich, and the Baugarten Stiftung (all to BT).

\section{References}

487

488

489

490

491

492

493

494

495

496

497

498

499

500

501

502

503

504

505

506

Abraham NM, Liu L, Jutras BL, Yadav AK, Narasimhan S, Gopalakrishnan V, Ansari JM, Jefferson KK, Cava F, Jacobs-Wagner C, Fikrig E. 2017. Pathogen-mediated manipulation of arthropod microbiota to promote infection. Proceedings of the National Academy of Sciences 114:E781-E790. DOI: 10.1073/pnas.1613422114.

Abrego N, Norberg A, Ovaskainen O. 2016. Measuring and predicting the influence of traits on the assembly processes of wood-inhabiting fungi. Journal of Ecology 105:1070-1081. DOI: 10.1111/1365-2745.12722

Adair KL, Douglas AE. 2017. Making a microbiome: the many determinants of host-associated microbial community composition. Current Opinion in Microbiology 35:23-29. DOI: 10.1016/j.mib.2016.11.002.

Aivelo T, Norberg A. 2017. Parasite-microbiota interactions potentially affect intestinal communities in wild mammals. Journal of Animal Ecology 87:438-447. DOI: 10.1111/1365-2656.12708.

Andersson M, Scherman K, Råberg L. 2013. Multiple-strain infections of Borrelia afzelii: a role for within-host interactions in the maintenance of antigenic diversity? The American naturalist 181:545-54. DOI: $10.1086 / 669905$.

Andersson M, Scherman K, Råberg L. 2014. Infection dynamics of the tick-borne pathogen "Candidatus Neoehrlichia mikurensis" and coinfections with Borrelia afzelii in bank voles in Southern Sweden. Applied and Environmental Microbiology 80:1645-9. DOI: 10.1128/AEM.03469-13.

Araújo MB, Rozenfeld A. 2014. The geographic scaling of biotic interactions. Ecography 37:406-415. DOI: 10.1111/j.1600-0587.2013.00643.x.

Archie E A, Ezenwa VO. 2011. Population genetic structure and history of a generalist parasite infecting multiple sympatric host species. International Journal for Parasitology 41:89-98. DOI: 10.1016/j.ijpara.2010.07.014.

Atkinson SF, Sarkar S, Aviña A, Schuermann JA, Williamson P. 2013. Modelling spatial concordance between

Peer] reviewing PDF | (2019:09:41295:1:1:NEW 3 Nov 2019) 
507

508

509

510

511

512

513

514

515

516

517

518

519

520

521

522

523

524

525

526

527

528

529

530

531

Rocky Mountain spotted fever disease incidence and habitat probability of its vector Dermacentor variabilis (American dog tick). Geospatial Health 7:91-100. DOI: 10.4081/gh.2012.108.

Belli A, Sarr A, Rais O, Rego ROM, Voordouw MJ. 2017. Ticks infected via co-feeding transmission can transmit Lyme borreliosis to vertebrate hosts. Scientific Reports 7:1-13. DOI: 10.1038/s41598-017-05231-1.

Bennie J, Huntley B, Wiltshire A, Hill MO, Baxter R, Wood CEHM, Ripton A, Pe C. 2008. Slope, aspect and climate : Spatially explicit and implicit models of topographic microclimate in chalk grassland. Ecological Modelling 6:47-59. DOI: 10.1016/j.ecolmodel.2008.04.010.

Bonnet SI, Binetruy F, Hernández-Jarguín AM, Duron O. 2017. The tick microbiome: Why non-pathogenic microorganisms matter in tick biology and pathogen transmission. Frontiers in Cellular and Infection Microbiology 7:236. DOI: 10.3389/fcimb.2017.00236.

Burri C, Schumann O, Schumann C, Gern L. 2014. Are Apodemus spp. mice and Myodes glareolus reservoirs for Borrelia miyamotoi, Candidatus Neoehrlichia mikurensis, Rickettsia helvetica, R. monacensis and Anaplasma phagocytophilum? Ticks and Tick-borne Diseases 5:245-251. DOI: 10.1016/j.ttbdis.2013.11.007.

Camacho C, Coulouris G, Avagyan V, Ma N, Papadopoulos J, Bealer K, Madden TL. 2009. BLAST+: architecture and applications. BMC bioinformatics 10:421. DOI: 10.1186/1471-2105-10-421.

Carey H V, Walters WA, Knight R. 2013. Seasonal restructuring of the ground squirrel gut microbiota over the annual hibernation cycle. American journal of physiology: Regulatory, integrative and comparative physiology 304:R33-42. DOI: 10.1152/ajpregu.00387.2012.

Carpi G, Cagnacci F, Wittekindt NE, Zhao F, Qi J, Tomsho LP, Drautz DI, Rizzoli A, Schuster SC. 2011. Metagenomic profile of the bacterial communities associated with Ixodes ricinus ticks. PloS One 6:e25604. DOI: 10.1371/journal.pone.0025604.

Chu H, Mazmanian SK. 2013. Innate immune recognition of the microbiota promotes host-microbial symbiosis. Nature Immunology 14:668-675. DOI: 10.1038/ni.2635.

Comstedt P, Jakobsson T, Bergström S. 2011. Global ecology and epidemiology of Borrelia garinii spirochetes. Infection Ecology Epidemiology 1:9545. DOI: 10.3402/iee.v1i0.9545. 
532 Cornetti L, Hilfiker D, Lemoine M, Tschirren B. 2018. Small-scale spatial variation in infection risk shapes the 533 evolution of a Borrelia resistance gene in wild rodents. Molecular Ecology:3515-3524. DOI:

$534 \quad 10.1111 /$ mec.14812.

535 Cornetti L, Lemoine M, Hilfiker D, Morger J, Reeh K, Tschirren B. 2016. Higher genetic diversity on mountain 536 tops: The role of historical and contemporary processes in shaping genetic variation in the bank vole. Biological Journal of the Linnean Society 118:233-244. DOI: 10.1111/bij.12723.

538
Cortinas MR, Guerra MA, Jones CJ, Kitron U. 2002. Detection, characterization, and prediction of tick-borne disease foci. International Journal of Medical Microbiology 291:11-20. DOI: 10.1016/S1438-4221(02)800030 .

Dallas T, Presley SJ. 2014. Relative importance of host environment, transmission potential and host phylogeny to the structure of parasite metacommunities. Oikos 123:866-874. DOI: 10.1111/oik.00707.

Diuk-Wasser MA, Vannier E, Krause PJ. 2016. Coinfection by Ixodes tick-borne pathogens: ecological, epidemiological, and clinical consequences. Trends in Parasitology 32:30-42. DOI: 10.1016/j.pt.2015.09.008.

Dormann CF, Bobrowski M, Dehling DM, Harris DJ, Hartig F, Lischke H, Moretti MD, Pagel J, Pinkert S, Schleuning M, Schmidt SI, Sheppard CS, Steinbauer MJ, Zeuss D, Kraan C. 2018. Biotic interactions in species distribution modelling: 10 questions to guide interpretation and avoid false conclusions. Global Ecology and Biogeography 27:1004-1016. DOI: 10.1111/geb.12759.

Durand J, Jacquet M, Paillard L, Rais O, Gern L, Voordouw MJ. 2015. Cross-immunity and community structure of a multiple-strain pathogen in the tick vector. Applied and Environmental microbiology 22. DOI: 10.1128/AEM.02296-15.

Elliot SL, Blanford S, Thomas MB. 2002. Host-pathogen interactions in a varying environment: temperature, behavioural fever and fitness. Proceedings of the Royal Society B: Biological Sciences 269:1599-607. DOI: 10.1098/rspb.2002.2067.

Engel P, Moran NA. 2013. The gut microbiota of insects - diversity in structure and function. FEMS Microbiology Reviews 37:699-735. DOI: 10.1111/1574-6976.12025.

Peer] reviewing PDF | (2019:09:41295:1:1:NEW 3 Nov 2019) 
557 Eremeeva ME, Dasch GA. 2015. Challenges Posed by tick-borne rickettsiae: eco-epidemiology and public health implications. Frontiers in Public Health 3:1-17. DOI: 10.3389/fpubh.2015.00055.

559

560

561

562

563

564

565

566

567

568

569

570

571

572

573

574

575

576

577

578

579

580

581
Eren AM, Borisy GG, Huse SM, Mark Welch JL. 2014. Oligotyping analysis of the human oral microbiome. Proceedings of the National Academy of Sciences 111:E2875-E2884. DOI: 10.1073/pnas.1409644111.

Eren AM, Maignien L, Sul WJ, Murphy LG, Grim SL, Morrison HG, Sogin ML. 2013. Oligotyping: Differentiating between closely related microbial taxa using 16S rRNA gene data. Methods in Ecology and Evolution 4:11111119. DOI: $10.1111 / 2041-210 X .12114$.

Estrada-Peña A, Cabezas-Cruz A, Pollet T, Vayssier-Taussat M, Cosson J-F. 2018. High throughput sequencing and network analysis disentangle the microbial communities of ticks and hosts within and between ecosystems. Frontiers in Cellular and Infection Microbiology 8:236. DOI: 10.3389/fcimb.2018.00236.

Gall CA, Reif KE, Scoles GA, Mason KL, Mousel M, Noh SM, Brayton KA. 2016. The bacterial microbiome of Dermacentor andersoni ticks influences pathogen susceptibility. ISME Journal 10:1846-1855. DOI: 10.1038/ismej.2015.266.

Gatewood AG, Liebman K, Vourc'h G, Bunikis J, Hamer S, Cortinas R, Melton F, Cislo P, Kitron U, Tsao J, Barbour AG, Fish D, Diuk-Wasser M. 2009. Climate and tick seasonality are predictors of Borrelia burgdorferi genotype distribution. Applied and Environmental Microbiology 75:2476-83. DOI: 10.1128/AEM.02633-08.

Gern L, Morán Cadenas F, Burri C. 2008. Influence of some climatic factors on Ixodes ricinus ticks studied along altitudinal gradients in two geographic regions in Switzerland. International Journal of Medical Microbiology 298:55-59. DOI: 10.1016/j.ijmm.2008.01.005.

Greay TL, Gofton AW, Paparini A, Ryan UM, Oskam CL, Irwin PJ. 2018. Recent insights into the tick microbiome gained through next-generation sequencing. Parasites and Vectors 11:12. DOI: 10.1186/s13071-017-2550-5.

Gurfield N, Grewal S, Cua LS, Torres PJ, Kelley ST. 2017. Endosymbiont interference and microbial diversity of the Pacific coast tick, Dermacentor occidentalis, in San Diego County, California. PeerJ 5:e3202. DOI: 10.7717/peerj.3202.

Peer] reviewing PDF | (2019:09:41295:1:1:NEW 3 Nov 2019) 
582 Haine ER. 2008. Symbiont-mediated protection. Proceedings of the Royal Society B: Biological Sciences 275:353-

583

584

585

586

587

588

589

590

591

592

593

594

595

596

597

598

599

600

601

602

603

604

605

606 361. DOI: 10.1098/rspb.2007.1211.

Halos L, Bord S, Cotté V, Gasqui P, Abrial D, Barnouin J, Boulouis HJ, Vayssier-Taussat M, Vourc'H G. 2010. Ecological factors characterizing the prevalence of bacterial tick-borne pathogens in Ixodes ricinus ticks in pastures and woodlands. Applied and Environmental Microbiology 76:4413-4420. DOI: 10.1128/AEM.00610-10.

Hammer TJ, Janzen DH, Hallwachs W, Jaffe SP, Fierer N. 2017. Caterpillars lack a resident gut microbiome. Proceedings of the National Academy of Sciences 114:9641-9646. DOI: 10.1073/pnas.1707186114.

Hanincova K, Schäfer SM, Etti S, Sewell HS, Taragelová V, Ziak D, Labuda M, Kurtenbach K. 2003a. Association of Borrelia afzelii with rodents in Europe. Parasitology 126:11-20. DOI: 10.1017/S0031182002002548.

Hanincova K, Taragelova V, Koci J, Schafer SM, Hails R, Ullmann AJ, Piesman J, Labuda M, Kurtenbach K. 2003b. Association of Borrelia garinii and B. valaisiana with songbirds in Slovakia. Applied and Environmental Microbiology 69:2825-2830. DOI: 10.1128/AEM.69.5.2825.

Hawlena H, Rynkiewicz E, Toh E, Alfred A, Durden LA, Hastriter MW, Nelson DE, Rong R, Munro D, Dong Q, Fuqua C, Clay K. 2013. The arthropod, but not the vertebrate host or its environment, dictates bacterial community composition of fleas and ticks. The ISME journal 7:221-3. DOI: 10.1038/ismej.2012.71.

Hawley DM, Altizer SM. 2011. Disease ecology meets ecological immunology: understanding the links between organismal immunity and infection dynamics in natural populations. Functional Ecology 25:48-60. DOI: 10.1111/j.1365-2435.2010.01753.x.

Herren JK, Lemaitre B. 2011. Spiroplasma and host immunity: Activation of humoral immune responses increases endosymbiont load and susceptibility to certain Gram-negative bacterial pathogens in Drosophila melanogaster. Cellular Microbiology 13:1385-1396. DOI: 10.1111/j.1462-5822.2011.01627.x.

Hillyard PD. 1996. Ticks of North-West Europe. Field Studies Council for the Linnean Society of London and the Estuarine and Coastal Sciences Association. London, UK.

Horner-Devine MC, Bohannan BJM. 2006. Phylogenetic clustering and overdispersion in bacterial communities. 
607

608

609

610

611

612

613

614

615

616

617

618

619

620

621

622

623

624

625

626

627

628

629

630

631

Ecology 87:100-108. DOI: 10.1890/0012-9658(2006)87[100:pcaoib]2.0.co;2.

Jaenike J, Unckless R, Cockburn SN, Boelio LM, Perlman SJ. 2013. Adaptation via symbiosis: recent spread of a Drosophila defensive symbiont. Science 329:212-215. DOI: 10.1126/science.1188235.

Jahfari S, Fonville M, Hengeveld P, Reusken C, Scholte E, Takken W, Heyman P, Medlock JM, Heylen D, Kleve J, Sprong H. 2012. Prevalence of Neoehrlichia mikurensis in ticks and rodents from North-west Europe. Parasites \& Vectors 5:74.

Jahfari S, Herremans T, Platonov AE, Kuiper H, Karan LS, Vasilieva O, Koopmans MPG, Hovius JWR, Sprong H. 2014. High seroprevalence of Borrelia miyamotoi antibodies in forestry workers and individuals suspected of human granulocytic anaplasmosis in the Netherlands. New Microbes and New Infections 2:144-149.

Jouda F, Perret J, Gern L. 2004a. Ixodes ricinus density, and distribution and prevalence of Borrelia burgdorferi sensu lato infection along an altitudinal gradient. Journal of Medical Entomology 41:162-169.

Jouda F, Perret J-L, Gern L. 2004b. Density of questing Ixodes ricinus nymphs and adults infected by Borrelia burgdorferi sensu lato in Switzerland: spatiotemporal pattern at a regional scale. Vector-borne and Zoonotic Diseases 4:23-32.

Kamvar ZN, Tabima JF, Grünwald NJ. 2014. Poppr : an R package for genetic analysis of populations with clonal, partially clonal, and/or sexual reproduction. PeerJ 2:e281. DOI: 10.7717/peerj.281.

Kawahara M, Rikihisa Y, Isogai E, Takahashi M, Misumi H, Suto C, Shibata S, Zhang C, Tsuji M. 2004. Ultrastructure and phylogenetic analysis of "Candidatus Neoehrlichia mikurensis" in the family Anaplasmataceae, isolated from wild rats and found in Ixodes ovatus ticks. International Journal of Systematic and Evolutionary Microbiology 54:1837-1843. DOI: 10.1099/ijs.0.63260-0.

Keesing F, Hersh MH, Tibbetts M, McHenry DJ, Duerr S, Brunner J, Killilea M, LoGiudice K, Schmidt KA, Ostfeld RS. 2012. Reservoir competence of vertebrate hosts for Anaplasma phagocytophilum. Emerging Infectious Diseases 18:2013-2016. DOI: 10.3201/eid1812.120919.

Keesing F, Holt RD, Ostfeld RS. 2006. Effects of species diversity on disease risk. Ecology Letters 9:485-98. DOI: 10.1111/j.1461-0248.2006.00885.x. 
632 Kozich JJ, Westcott SL, Baxter NT, Highlander SK, Schloss PD. 2013. Development of a dual-index sequencing 633 strategy and curation pipeline for analyzing amplicon sequence data on the MiSeq Illumina sequencing 634 platform. Applied and Environmental Microbiology 79:5112-20. DOI: 10.1128/AEM.01043-13.

635 Laaksonen M, Klemola T, Feuth E, Sormunen JJ, Puisto A, Mäkelä S, Penttinen R, Ruohomäki K, Hänninen J, 636 Sääksjärvi IE, Vuorinen I, Sprong H, Hytönen J, Vesterinen EJ. 2018. Tick-borne pathogens in Finland: comparison of Ixodes ricinus and I. persulcatus in sympatric and parapatric areas. Parasites \& Vectors 11:556.

Lawson CR, Bennie J, Hodgson JA, Thomas CD, Wilson RJ. 2014. Topographic microclimates drive microhabitat associations at the range margin of a butterfly. Ecography 37:732-740. DOI: 10.1111/ecog.00535. control specificity and stability of the gut microbiota. Nature 501:426-429. DOI: 10.1038/nature12447.

Lello J, Boag B, Fenton A, Stevenson IR, Hudson PJ. 2004. Competition and mutualism among the gut helminths of a mammalian host. Nature 428:20-24. DOI: 10.1038/nature02472.1.

Lemoine M, Cornetti L, Tschirren B. 2018. Does Borrelia burgdorferi sensu lato facilitate the colonisation of marginal habitats by Ixodes ricinus? A correlative study in the Swiss Alps. bioRxiv. DOI: 10.1101/273490.

Lo N, Beninati T, Sassera D, Bouman EAP, Santagati S, Gern L, Sambri V, Masuzawa T, Gray JS, Jaenson TGT, Bouattour A, Kenny MJ, Guner ES, Kharitonenkov IG, Bitam I, Bandi C. 2006. Widespread distribution and by emerging zoonotic pathogens in Western Switzerland. Applied and Environmental Microbiology 78:4606Ixodidae) inhibits transovarial transmission of a second Rickettsia. Journal of Medical Entomology 39:809813. DOI: $10.1603 / 0022-2585-39.6 .809$. 
657 MacDonald AJ, Hyon DW, Iii JBB, Connor KEO, Swei A, Briggs CJ. 2017. Lyme disease risk in southern 658 California : abiotic and environmental drivers of Ixodes pacificus (Acari: Ixodidae) density and infection 659 prevalence with Borrelia burgdorferi. Parasites \& Vectors:7. DOI: 10.1186/s13071-016-1938-y.

660

661

662

663

664

665

666

667

668

669

670

671

672

673

674

675

676

677

678

679

680

681

Mannelli A, Bertolotti L, Gern L, Gray J. 2012. Ecology of Borrelia burgdorferi sensu lato in Europe: transmission dynamics in multi-host systems, influence of molecular processes and effects of climate change. FEMS Microbiological Reviews 36:837-61. DOI: 10.1111/j.1574-6976.2011.00312.x.

McCain CM. 2005. Elevational gradients in diversity of small mammals. Ecology 86:366-372.

McCoy KD, Chapuis E, Tirard C, Boulinier T, Michalakis Y, Le Bohec C, Le Maho Y, Gauthier-Clerc M. 2005. Recurrent evolution of host-specialized races in a globally distributed parasite. Proceedings of the Royal Society B: Biological Sciences 272:2389-2395. DOI: 10.1098/rspb.2005.3230.

McCoy KD, Léger E, Dietrich M. 2013. Host specialization in ticks and transmission of tick-borne diseases: a review. Frontiers in Cellular and Infection Microbiology 3:57. DOI: 10.3389/fcimb.2013.00057.

Medlock JM, Hansford KM, Bormane A, Derdakova M, Estrada-Peña A, George J-C, Golovljova I, Jaenson TGT, Jensen J-K, Jensen PM, Kazimirova M, Oteo J, Papa A, Pfister K, Plantard O, Randolph SE, Rizzoli A, Santos-Silva MM, Sprong H, Vial L, Hendrickx G, Zeller H, Van Bortel W. 2013. Driving forces for changes in geographical distribution of Ixodes ricinus ticks in Europe. Parasites \& vectors 6:1. DOI: 10.1186/17563305-6-1.

Michelet L, Delannoy S, Devillers E, Umhang G, Aspan A, Juremalm M, Chirico J, van der Wal FJ, Sprong H, Boye Pihl TP, Klitgaard K, Bødker R, Fach P, Moutailler S. 2014. High-throughput screening of tick-borne pathogens in Europe. Frontiers in Cellular and Infection Microbiology 4:103. DOI: 10.3389/fcimb.2014.00103.

Moutailler S, Valiente Moro C, Vaumourin E, Michelet L, Tran FH, Devillers E, Cosson JF, Gasqui P, Van VT, Mavingui P, Vourc'h G, Vayssier-Taussat M. 2016. Co-infection of ticks: the rule rather than the exception. PLoS Neglected Tropical Diseases 10:e004539. DOI: 10.1371/journal.pntd.0004539.

Narasimhan S, Rajeevan N, Liu L, Zhao YO, Heisig J, Pan J, Eppler-Epstein R, Deponte K, Fish D, Fikrig E. 2014. 
682 Gut microbiota of the tick vector Ixodes scapularis modulate colonization of the Lyme disease spirochete. Cell Host and Microbe 15:58-71. DOI: 10.1016/j.chom.2013.12.001.

684

685

686

687

688

689

690

691

692

693

694

695

696

697

698

699

700

701

702

703

704

705

706

Norman RA, Worton AJ, Gilbert L. 2016. Past and future perspectives on mathematical models of tick-borne pathogens. Parasitology 143:850-859. DOI: 10.1017/S0031182015001523.

Ovaskainen O, Abrego N, Halme P, Dunson D. 2015. Using latent variable models to identify large networks of species-to-species associations at different spatial scales. Methods in Ecology and Evolution 7:549-555. DOI: 10.1111/2041-210X.12501.

Ovaskainen O, Gleb Tikhonov, Norberg A, Blanchet FG, Duan L, Dunson D, Roslin T, Abrego N. 2017a. How to make more out of community data? A conceptual framework and its implementation as models and software. Ecology Letters 20:561-576. DOI: 10.1111/ele.12757.

Ovaskainen O, Tikhonov G, Dunson D, Grøtan V, Engen S, Sæther B-E, Abrego N. 2017b. How are species interactions structured in species-rich communities? A new method for analysing time-series data. Proceedings of the Royal Society B: Biological Sciences 284:20170768.

Petney TN, Andrews RH. 1998. Multiparasite communities in animals and humans: frequency, structure and pathogenic significance. International Journal for Parasitology 28:377-393.

R Core Team. 2013. R: A language and environment for statistical computing.

Randolph SE, Miklisová D, Lysy J, Rogers DJ, Labuda M. 1999. Incidence from coincidence: Patterns of tick infestations on rodents facilitate transmission of tick-borne encephalitis virus. Parasitology 118:177-186. DOI: $10.1017 / \mathrm{S} 0031182098003643$.

Rigaud T, Perrot-Minnot M-J, Brown MJF. 2010. Parasite and host assemblages: embracing the reality will improve our knowledge of parasite transmission and virulence. Proceedings of the Royal Society B: Biological Sciences 277:3693-3702. DOI: 10.1098/rspb.2010.1163.

Rodríguez M, Terrazas LI, Márquez R, Bojalil R. 1999. Susceptibility to Trypanosoma cruzi is modified by a previous non-related infection. Parasite Immunology 21:177-185. DOI: 10.1046/j.1365-3024.1999.00218.x.

Rosà R, Andreo V, Tagliapietra V, Baráková I, Arnoldi D, Hauffe H, Manica M, Rosso F, Blaňarová L, Bona M, 
707

708

709

710

711

712

713

714

715

716

717

718

719

720

721

722

723

724

725

726

727

728

729

730

731

Derdáková M, Hamšíková Z, Kazimírová M, Kraljik J, Kocianová E, Mahríková L, Minichová L, Mošanský L, Slovák M, Stanko M, Špitalská E, Ducheyne E, Neteler M, Hubálek Z, Rudolf I, Venclikova K, Silaghi C, Overzier E, Farkas R, Földvári G, Hornok S, Takács N, Rizzoli A. 2018. Effect of climate and land use on the spatiotemporal variability of tick-borne bacteria in Europe. International Journal of Environmental Research and Public Health 15:732. DOI: 10.3390/ijerph15040732.

Ross BD, Hayes B, Radey MC, Lee X, Josek T, Bjork J, Neitzel D, Paskewitz S, Chou S, Mougous JD. 2018. Ixodes scapularis does not harbor a stable midgut microbiome. ISME Journal 12:2596-2607. DOI: 10.1038/s41396018-0161-6.

Sofonea MT, Alizon S, Michalakis Y. 2015. From within-host interactions to epidemiological competition: A general model for multiple infections. Philosophical Transactions of the Royal Society B: Biological Sciences 370:20140303. DOI: 10.1098/rstb.2014.0303.

Sprong H, Wielinga PR, Fonville M, Reusken C, Brandenburg AH, Borgsteede F, Gaasenbeek C, Van Der Giessen JW. 2009. Ixodes ricinus ticks are reservoir hosts for Rickettsia helvetica and potentially carry flea-borne Rickettsia species. Parasites and Vectors 2:41. DOI: 10.1186/1756-3305-2-41.

Stuen S, Granquist EG, Silaghi C. 2013. Anaplasma phagocytophilum —a widespread multi-host pathogen with highly adaptive strategies. Frontiers in Cellular and Infection Microbiology 3:31. DOI: 10.3389/fcimb.2013.00031.

Swei A, Kwan JY. 2017. Tick microbiome and pathogen acquisition altered by host blood meal. ISME Journal 11:813-816. DOI: 10.1038/ismej.2016.152.

Swei A, Meentemeyer R, Briggs CJ. 2011. Influence of abiotic and environmental factors on the density and infection prevalence of Ixodes pacificus (Acari: Ixodidae) with Borrelia burgdorferi. Journal of Medical Entomology 48:20-28. DOI: 10.1603/ME10131.

Thornton PE, Running SW, White MA. 1997. Generating surfaces of daily meteorological variables over large regions of complex terrain. Journal of Hydrology 190:214-251.

Tikhonov G, Abrego N, Dunson D, Ovaskainen O. 2017. Using joint species distribution models for evaluating how 
732

733

734

735

736

737

738

739

740

741

742

743

744

745

746

747

748

749

750

751

752

753

754

755

756

species-to-species associations depend on the environmental context. Methods in Ecology and Evolution 8:443-452. DOI: 10.1111/2041-210X.12723.

van Treuren W, Ponnusamy L, Brinkerhoff RJ, Gonzalez A, Parobek CM, Juliano JJ, Andreadis TG, Falco RC, Ziegler LB, Hathaway N, Keeler C, Emch M, Bailey JA, Roe RM, Apperson CS, Knight R, Meshnick SR. 2015. Variation in the microbiota of Ixodes ticks with regard to geography, species, and sex. Applied and Environmental Microbiology 81:6200-6209. DOI: 10.1128/AEM.01562-15.

Vayssier-Taussat M, Moutailler S, Michelet L, Devillers E, Bonnet S, Cheval J, Hebert C, Eloit M. 2013. Next generation sequencing uncovers unexpected bacterial pathogens in ticks in western Europe. PLoS ONE 8:e81439. DOI: 10.1371/journal.pone.0081439.

Venclikova K, Rudolf I, Mendel J, Betasova L, Hubalek Z. 2014. Rickettsiae in questing Ixodes ricinus ticks in the Czech Republic. Ticks and Tick-borne Diseases 5:135-138. DOI: 10.1016/j.ttbdis.2013.09.008.

Wagemakers A, Staarink PJ, Sprong H, Hovius JWR. 2015. Borrelia miyamotoi: A widespread tick-borne relapsing fever spirochete. Trends in Parasitology 31:260-269. DOI: 10.1016/j.pt.2015.03.008.

Warton DI, Blanchet FG, O’Hara RB, Ovaskainen O, Taskinen S, Walker SC, Hui FKC. 2015. So many variables: joint modeling in community ecology. Trends in Ecology \& Evolution 30:766-779. DOI: 10.1016/j.tree.2015.09.007.

West SA, Buckling A. 2003. Cooperation, virulence and siderophore production in bacterial parasites. Proceedings of the Royal Society B: Biological Sciences 270:37-44. DOI: 10.1098/rspb.2002.2209.

Xie J, Vilchez I, Mateos M. 2010. Spiroplasma bacteria enhance survival of Drosophila hydei attacked by the parasitic wasp Leptopilina heterotoma. PLoS ONE 5:e12149. DOI: 10.1371/journal.pone.0012149.

Zolnik CP, Falco RC, Daniels TJ, Kolokotronis SO. 2018. Transient influence of blood meal and natural environment on blacklegged tick bacterial communities. Ticks and Tick-borne Diseases 9:563-572. DOI: 10.1016/j.ttbdis.2018.01.007.

Zolnik CP, Prill RJ, Falco RC, Daniels TJ, Kolokotronis SO. 2016. Microbiome changes through ontogeny of a tick pathogen vector. Molecular ecology 25:4963-4977. DOI: 10.1111/mec.13832.

Peer] reviewing PDF | (2019:09:41295:1:1:NEW 3 Nov 2019) 
757 Zurell D, Pollock LJ, Thuiller W. 2018. Do joint species distribution models reliably detect interspecific interactions from co-occurrence data in homogenous environments? Ecography 41:1812-1819. DOI: 10.1111/ecog.03315. 


\section{Table 1 (on next page)}

Tick sampling sites in the Swiss Alps. 
1 Table 1: Tick sampling sites in the Swiss Alps.

\begin{tabular}{|c|c|c|c|c|c|c|c|}
\hline \multirow[t]{3}{*}{ Locatio } & \multirow[t]{3}{*}{ Site } & \multicolumn{2}{|c|}{ Coordinates } & \multirow[t]{2}{*}{ Elevation } & \multicolumn{3}{|c|}{ Succesfully sequenced Ixodes } \\
\hline & & \multirow[b]{2}{*}{ North } & \multirow[b]{2}{*}{ East } & & \multicolumn{3}{|c|}{ ricinus ticks } \\
\hline & & & & (masl) & nymphs & males & females \\
\hline \multirow[t]{3}{*}{1} & Sagogn & 46.783 & 9.233 & 693 & 0 & 9 & 15 \\
\hline & Flims & 46.827 & 9.280 & 1138 & 3 & 5 & 3 \\
\hline & Ruschein & 46.795 & 9.169 & 1454 & 0 & 1 & 1 \\
\hline \multirow[t]{3}{*}{2} & Rodels & 46.760 & 9.425 & 630 & 2 & 5 & 4 \\
\hline & Tomils & 46.772 & 9.453 & 1144 & 3 & 6 & 4 \\
\hline & Feldis & 46.789 & 9.453 & 1673 & 1 & 1 & 0 \\
\hline \multirow[t]{3}{*}{3} & Passug & 46.840 & 9.538 & 732 & 0 & 5 & 6 \\
\hline & Castiel & 46.826 & 9.569 & 1094 & 0 & 3 & 3 \\
\hline & Praden & 46.817 & 9.589 & 1582 & 1 & 0 & 1 \\
\hline
\end{tabular}

2 


\section{Table 2 (on next page)}

Common tick endosymbionts and/or putative human pathogens observed in I. ricinus ticks.

See Supplementary Materials for information on OTU assignment. 
1 Table 2: Common tick endosymbionts and/or putative human pathogens observed in I. ricinus ticks. See

2 Supplementary Materials for information on OTU assignment.

\begin{tabular}{|c|c|c|c|}
\hline OTU & Label & $\begin{array}{l}\text { Human pathogen / } \\
\text { tick endosymbiont }\end{array}$ & $\begin{array}{l}\text { Occurrence (\% of } \\
\text { analyzed ticks) }\end{array}$ \\
\hline Otu0001 & Midichloria & endosymbiont & 100 \\
\hline Otu0003 & Spiroplasma & endosymbiont & 41 \\
\hline Otu0005 & Rickettsiella & endosymbiont & 63 \\
\hline Otu0021 & Lariskella & endosymbiont & 49 \\
\hline \multirow[t]{2}{*}{ Otu0031 } & Rickettsia helvetica & both & 16 \\
\hline & R. monacensis & both & 6 \\
\hline Otu0067 & Rickettsia sp. & both & 25 \\
\hline Otu0076 & Anaplasma & both & 33 \\
\hline \multirow[t]{2}{*}{ Otu0086 } & Candidatus & both & 22 \\
\hline & Neoehrlichia & & \\
\hline \multirow[t]{4}{*}{ Otu0088 } & Borrelia afzelii & pathogen & 9 \\
\hline & B. miyamotoi & pathogen & 10 \\
\hline & B. garinii & pathogen & 6 \\
\hline & B. valaisiana & pathogen & 2 \\
\hline
\end{tabular}

3 


\section{Table 3 (on next page)}

Associations between tick-specific and environmental variables and the occurrence of endosymbionts and human pathogens in I. ricinus ticks.

A positive sign indicates that higher variable values are associated with a higher probability of OTU occurrence. A higher aspect value means that a site is facing northwards. Only associations with strong statistical support (based on the $90 \%$ central credible interval) are presented. 
1 Table 3. Associations between tick-specific and environmental variables and the occurrence of

2 endosymbionts and human pathogens in I. ricinus ticks. A positive sign indicates that higher variable

3 values are associated with a higher probability of OTU occurrence. A higher aspect value means that a

4 site is facing northwards. Only associations with strong statistical support (based on the $90 \%$ central

5 credible interval) are presented.

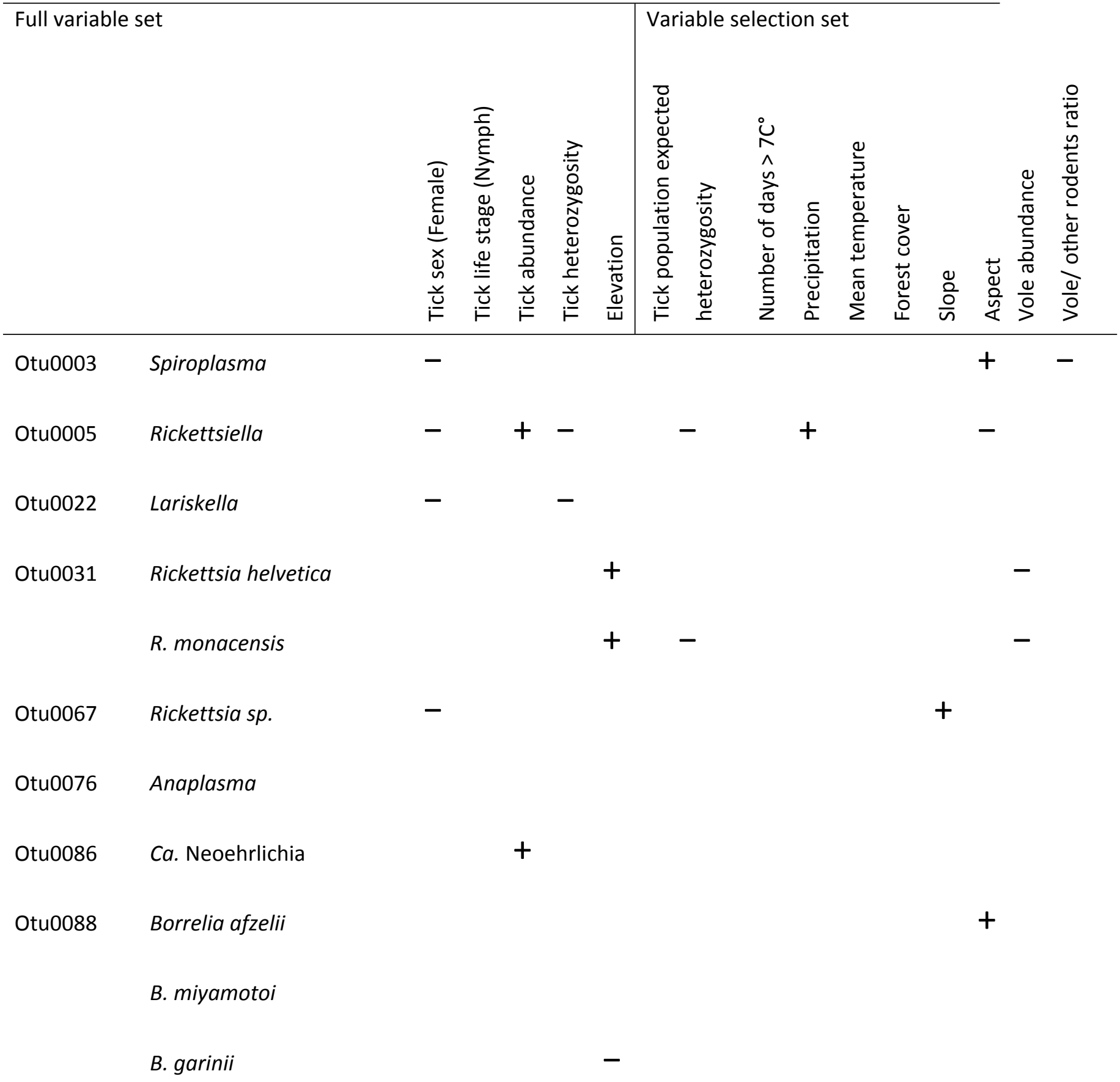


Figure 1

Location of tick sampling sites in the Swiss Alps.

Different shapes (i.e., circle, square and triangle) represent the different locations and different colours represent elevation (white: low, grey: middle, black: high). Rivers and motorway are shown in black. Map data @ 2019 Google, GeoBasis-DE/BKG.

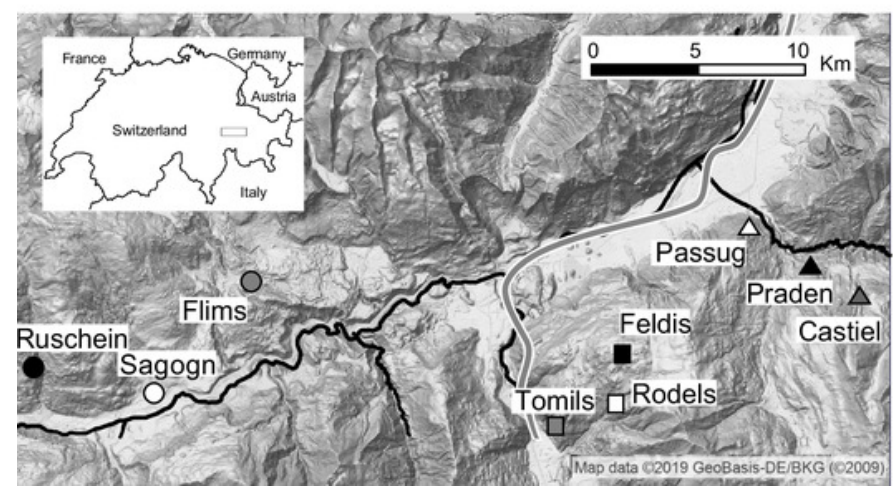




\section{Figure 2}

Tick microbial community variance partitioning for different fixed and random effects.

The first three columns represent tick endosymbionts, the next three columns are OTUs which are both tick endosymbionts and human pathogens and the subsequent six columns

represent human pathogens. The other columns represent the 88 most common OTUs found in I. ricinus, ordered by read frequency. Month, sampling site, location and tick ID were included in the model as random effects, whereas fixed effects were divided into environmental (elevation, temperature, precipitation, forest coverage, slope, aspect, vole abundance and vole-to-other-rodents ratio) and tick-specific variables (life stage or sex, individual heterozygosity, abundance, expected population heterozygosity). See raw data in Figshare for information on OTU labels. 


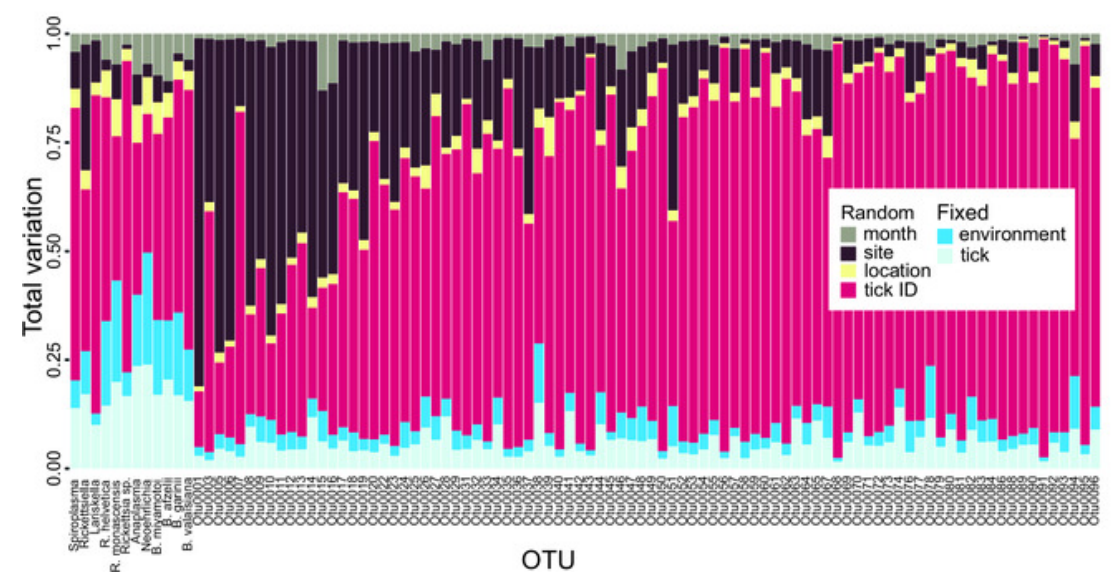




\section{Figure 3}

Residual association patterns among endosymbionts and human pathogens within ticks on a) individual tick-level and b) on site-level after accounting for shared environmental preference.

Red lines represent positive associations and blue lines negative associations. Only associations with strong statistical support (i.e., based on the $90 \%$ central credible interval) are presented. Darker colors indicate stronger associations.

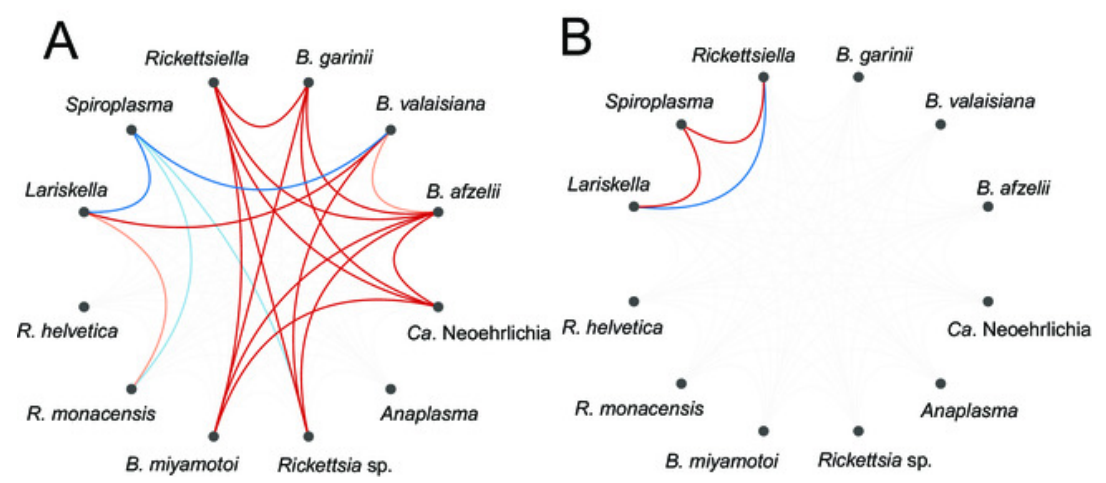

